\title{
Errors That Occur from Using an Inappropriate Thermal Buffer When Monitoring the Storage Conditions of Temperature Sensitive Products: Size and Material DO Matter
}

Michael R. Rusnack; Ray Sasso; Anthony Beers

AmericanPharma Technologies

This is a continuation of the first article submitted and published at Innovations in pharmacy, https://pubs.lib.umn.edu/index.php/innovations/authorDashboard/submission/962

\begin{abstract}
Common practice in the monitoring of cold chain conditions for temperature sensitive products is to employ a physical thermal buffer into which the temperature probe is inserted. This buffer may be a bottle of glycol or other liquid, a container of glass beads, aluminum block or nearly any other media the user feels appropriate. The purpose of the buffer is to simulate the experience of the stored product rather than the air temperature. Obviously, this mission will not be accomplished to the extent that the physical buffer is not matched to the thermal properties of the stored product and its container. Cold chain managers are faced with a complex problem if they attempt to take this issue into account. Furthermore, a match is not possible with a single physical buffer when the cold storage unit contains different products or size containers. This paper quantifies the results of this mismatch from various factors and suggests possible solutions to this dilemma.
\end{abstract}

Keywords: cold chain glycol storage, temperature buffer, temperature monitoring, vaccines

\section{Overview}

It is common in the cold chain monitoring of pharmaceuticals, vaccines, tissue and other temperature sensitive materials to require a temperature buffer consisting of a physical container into which the temperature probe is inserted. At the time of authoring this paper, there is no recommended or standard procedure for selecting this buffer. (Aldous, 2017) In fact, the specifics of the physical buffer--size, shape, and material--are very rarely consciously selected, but established by default to whatever the company providing the temperature probe uses. A review of physical thermal buffers currently provided by these companies shows little consistency in any of these parameters. Volumes can range from 10 to $300 \mathrm{ml}$ glycol vials, as well as machined and preformed blocks of aluminum, plastic or silicone. The Centers for Disease Control and Prevention recommends a $20 \mathrm{ml}$ Boston Bottle filled with equal amount of water and glycol. The purpose of the water/glycol mixture is to prevent freezing of the buffering solution (CDC, January). However, the stored goods monitored by this buffer were observed to include pre-filled syringes as small as $0.25 \mathrm{ml}$ to bottles and vials many times that volume.

The two purposes of the buffered temperature probe are somewhat in opposition to each other. A larger volume buffer will prevent "false" alerting from transient changes caused by regular use, however, that same buffer may to fail to respond quickly enough to freezing or warming events in time to

Corresponding author: Michael R. Rusnack

AmericanPharma Technologies

michael.rusnack@ameri-pharma.com prevent spoilage of the storage unit's contents. Both objectives can only be achieved when the buffer is thermally matched to the stored goods.

\section{Materials and Methods}

When storing pharmaceuticals and other temperature sensitive products, each stored good must be stored according to the manufacturer's specifications. Most often the recommended temperature range is between $2^{\circ} \mathrm{C}$ and $8^{\circ} \mathrm{C}$ $\left(36^{\circ} \mathrm{F}\right.$ and $\left.46^{\circ} \mathrm{F}\right)$ for refrigerators and between $-50^{\circ} \mathrm{C}$ and $-15^{\circ}$ $\mathrm{C}\left(-58^{\circ} \mathrm{F}\right.$ and $\left.+5^{\circ} \mathrm{F}\right)$ for freezers

Temperature excursions, short or long, cooling or warming, must be represented accurately to understand the effect on the stored contents. This is usually accomplished through periodic temperature reporting, with the intervals between readings varying from 5 to 30 minutes. While a short time excursion may not be damaging to the stored goods, the cumulative effects of repeated short events may degrade the contents. (GDP Question: When to use Mean Kinetic Temperature Calculation (MKT)?, 2014) This is especially true for the freezing of refrigerated goods where even a very brief freeze can destroy the stored goods. Consequently, it is of utmost importance to represent the temperature of the contents accurately when describing and recording the storage environment.

Glycol, beads, and sand are all used as a buffering material. All these loose media are subject to spill during normal access to the storage unit. This may have been the impetus for the development of the solid media buffers. These include 
temperature probes embedded in aluminum, Teflon ${ }^{\mathrm{TM}}$, or silicone forms. It is with these buffers that the thermal properties of the buffer are most influential.

Each buffer material has unique and varying physical properties. One such property is the Specific Heat Capacity $\left(C_{p}\right)$ - Heat capacity or thermal capacity is a measurable physical quantity equal to the ratio of the heat added to (or removed from) an object to the resulting temperature change. (Resnick, 2013) For example, the specific heat of water is $4.18 \mathrm{~J} / \mathrm{g}{ }^{\circ} \mathrm{C}$.

The terms that are used in the equation for calculating the specific heat of a substance are:

- Delta $\mathrm{T}$ or $\Delta \mathrm{T}$ - the difference between the first temperature T(1) and the second temperature T(2)

- Mass $m$ - the mass of the sample

- Heat Q - the amount of heat in Joules J

- $\quad$ Specific Heat $C_{p}$

The relationship between heat $Q$ and temperature change $\Delta T$ is usually expressed in the form shown below.

$$
Q=C_{p} \mathrm{~m} \Delta \mathrm{T}
$$

\section{Equation 1 - Heat Transfer Rate Formula}

This formula describes what is known as the Lump Capacitance Model (LCM). Not all materials are accurately characterized by the LCM. To determine if our buffer material is one of them we compute what is known as the Biot number.

The Biot number (Bi) is computed as:

$$
B i=\frac{L_{c} h}{C_{p}}
$$

\section{Equation 2 - Biot Number Formula}

where:

- $L_{c}$ - the ratio of the Volume to the Surface area $V / A_{s}$

- $h$ - the conductive heat transfer of the storage unit, air $=100 \mathrm{w} / \mathrm{m}^{2} \mathrm{~K}$

- $\quad C_{p}$ - the heat capacity of the buffer material (see table 1) J/kg K

Biot values less than 0.1 imply that the heat conduction inside the thermal body is much faster than the heat convection away from the surface. This situation allows the use of the lumped capacitance model.

\begin{tabular}{|l|c|}
\hline \multicolumn{1}{|c|}{ Material } & Bi \\
\hline Aluminum & 0.00132 \\
\hline Ethylene Glycol, 50\% & 0.00036 \\
\hline Glass Beads & 0.00141 \\
\hline Sand & 0.00129 \\
\hline Silicon, RTV & 0.00099 \\
\hline Teflon $^{\circledR}$ & 0.00094 \\
\hline Water $^{\text {Wat }}$ & 0.00028 \\
\hline
\end{tabular}

Table 1 - Computed Biot Number (Bi) for Select Buffer Materials

The values in Table 1 were computed assuming a cylindrically shaped container. Since all the Biot values are considerably less than 0.1 we can rely upon the Lump Capacitance Model to describe the thermal reactivity of these materials.

The calculation of Specific Heat Capacity for our sample of buffer materials is shown in Table 2 below. We have included the density of each material as well to account for the differences in size of buffers.

\begin{tabular}{|l|r|r|}
\hline \multicolumn{1}{|c|}{ Material } & \multicolumn{1}{c|}{$\begin{array}{c}\boldsymbol{C}_{\boldsymbol{p}} \\
\text { Specific } \\
\text { Heat }\end{array}$} & $\begin{array}{c}\boldsymbol{p} \\
\text { Density }\end{array}$ \\
\hline Aluminum & \multicolumn{1}{c|}{$\mathbf{J} / \mathbf{k g ~ K}$} & $\mathbf{w} / \mathbf{m}^{\mathbf{3}}$ \\
\hline Ethylene Glycol, 50\% & 897 & 2700 \\
\hline Glass Beads & 3270 & 1110 \\
\hline Sand & 840 & 1500 \\
\hline Silicon, RTV & 920 & 2660 \\
\hline Teflon ${ }^{\circledR}$ & 1200 & 120 \\
\hline Water & 1260 & 2200 \\
\hline
\end{tabular}

Table 2 - Specific Heat and Density of Buffer Materials (Specific Heat of Solids, n.d.)

Glass beads pose an additional challenge. Unlike a fluid or fine sand, the spherical shape of the beads does not fill the entire volume with the buffer material. This problem is addressed by answering an age-old carnival question "how many candies are in the jar?" Researchers at New York University (N.Y.U.) (Peeples, 2009) may finally have the answer to this classic mathematical puzzle. Their analysis determines that the randomly packed identical spheres fill up about 64 percent of the volume in each container. When sizing a glass bead buffer, this must be considered.

Given a standard of glycol volume and its equivalents, implementation of volumes greater or lesser would present a mismatch with the intended thermal response. The larger the buffer, the slower the temperature monitor will respond to the changes in temperature. Likewise, a buffer that is too small will fail to dampen the storage unit fluctuations which will result in false alerts during regular use and operation. 
For example the, $C D C$ guidance for monitoring vaccines specifies the requirement for a thermal buffer but does not state how large or small it should be or what it should be made from. It does note, however; the purpose is defined below.

“...a buffered temperature probe, which is
the most accurate way to measure actual
vaccine temperatures. Temperatures
measured by a buffered probe match
vaccine temperature more closely than
those measured by standard thermometers,
which tend instead to reflect air
temperature."

As shown above in equation 1, to represent the actual vaccine temperature, it is necessary to consider the material and size or mass of the volume of the buffer.

Figures 1 and 2 below demonstrates the effect of the material and volume of the buffer. The data was developed using the following conditions. A stored material, e.g. vaccine is maintained at $4^{\circ} \mathrm{C}$, the storage unit is subjected to an inrush of air that results in an air temperature increase to $12^{\circ} \mathrm{C}$. Using the selected buffers and volumes, how many minutes would it take for the stored good to reach a critical temperature of $8^{\circ} \mathrm{C}$ ?
The circumstances described herein are of a monitoring solution that is designed to alert when the represented contents exceed the upper control limit of $8^{\circ} \mathrm{C}$. In this example, the stored contents are vaccines which are made up of mostly water. For the purposes of this demonstration, the stored good is in a $20 \mathrm{ml}$ cylindrical container. From the graph, it can be determined that the contents would reach the $8^{\circ} \mathrm{C}$ limit in approximately five (5) minutes. Further, the same material (water) using a $50 \mathrm{ml}$ buffer would not alert until 12 minutes. In this case, an improperly sized buffer would result in a delay of more than seven (7) minutes. It can be seen from the demonstration one can determine how the buffer size and material affect the time to alert.

Figure $1 \mathrm{a}$ and Figure $1 \mathrm{~b}$ below demonstrates the effect of the selection of common buffer materials. In this presentation, the volume of the buffer remains constant, while the material is changed. In each case, a $20 \mathrm{ml}$ volume of material is chosen. Except for glycol, the results indicate that none of the chosen buffer materials accurately represent the stored goods. To accurately represent the stored good, one must increase the size of each of the other buffers to match the characteristics of the stored good.
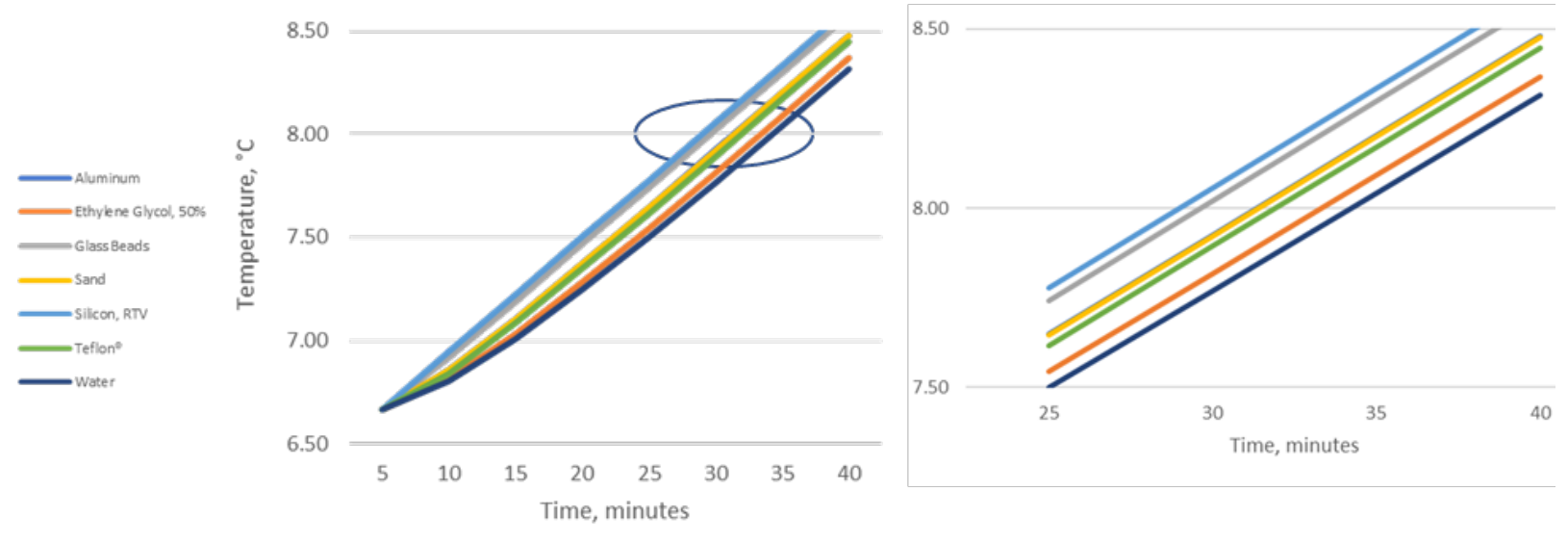

Figure $1 \mathrm{a}$ and $\mathbf{1 b}$ - Time to Temperature in Minutes for Various Buffer Material 


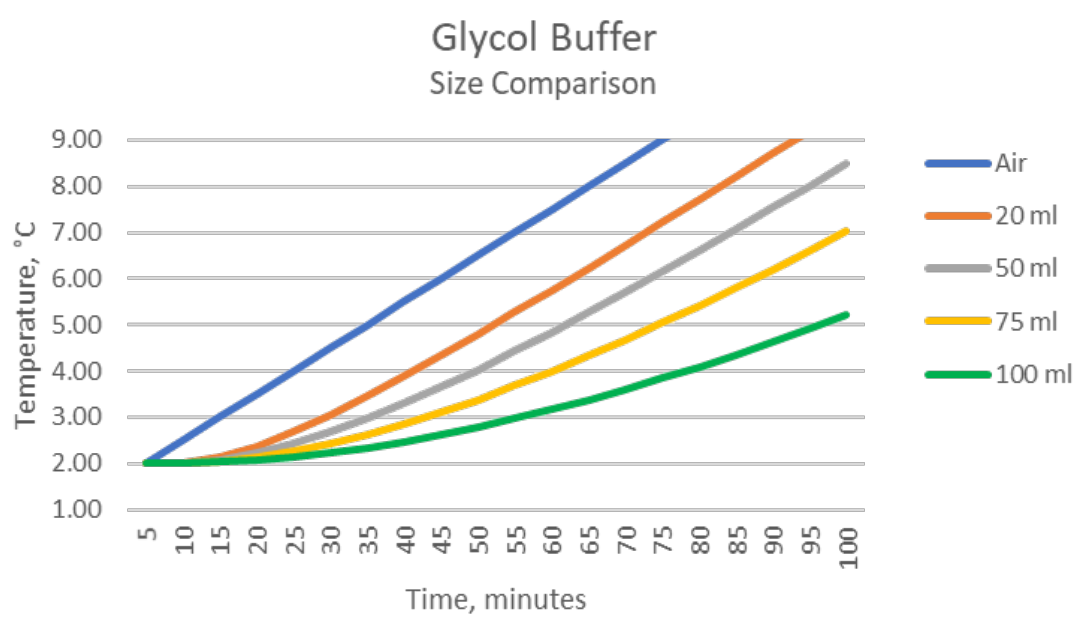

Figure 2 -Buffer Size Response Comparison (Warming)

Figure 2 demonstrates the result of applying different volumes of glycol buffers to the same warming data. In this case, the warming of the refrigerator is shown (fault condition - door ajar). The difference between a $20 \mathrm{ml}$ and $50 \mathrm{ml}$ buffer reaching the 8.0 -degree level is 15 minutes. For a $100 \mathrm{ml}$ buffer this difference is 60 minutes.

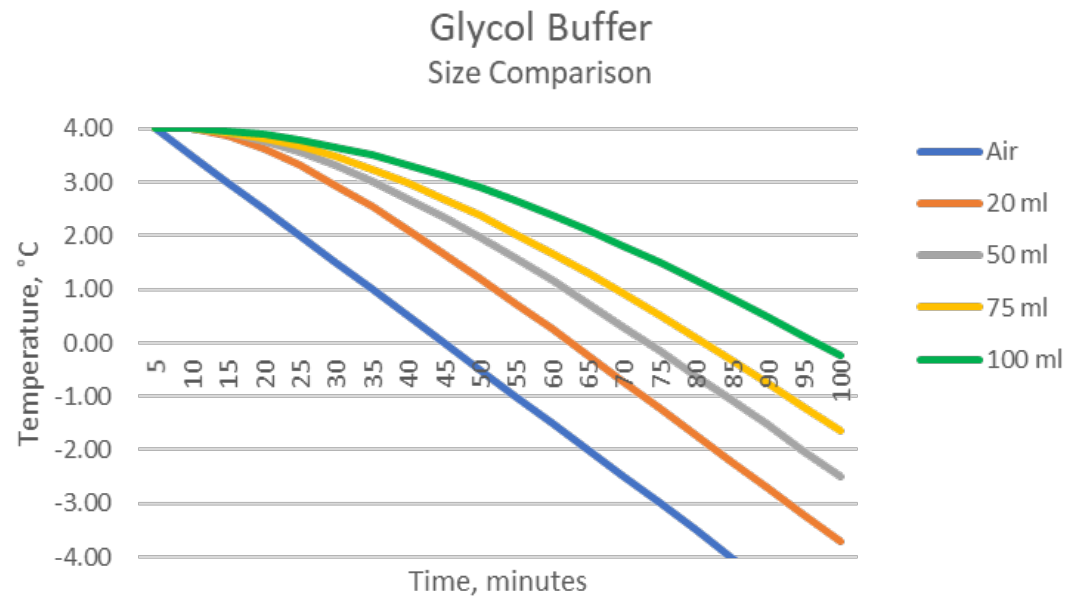

Figure 3 -Buffer Size Response Comparison (Freezing)

Figure 3 demonstrates the result of applying different volumes of glycol buffers to a cooling situation. (fault condition - stuck thermostat). When comparing the temperature of the air to the other buffer volumes, we can see the difference in the time it takes each buffer to reach freezing. Since the temperature probe is inserted in this buffer the storage manager would be aware of a freezing condition in widely different time frames.

\section{Virtual Buffering}

One solution to the problems identified above is a concept called "virtual buffering". This method involves a mathematical calculation to COMPUTE the temperature inside a container of known material based upon the thermodynamic equations and the temperature of the surrounding air. 
The calculations involved with this method are not complicated, and are shown below:

$$
\begin{aligned}
& \frac{d Q}{d t}=C_{p} A \frac{d}{d t}(\Delta T) \\
& C_{p}=\text { thermal conductivity constant } \\
& \mathrm{A}=\mathrm{describes} \text { the stored container geometry } \\
& \mathrm{d} \Delta \mathrm{T} / \mathrm{dt}=\text { Temperature gradient } \\
& \mathrm{dQ} / \mathrm{dt} \text { is proportional to } \mathrm{T}_{0}-\mathrm{T}_{\text {ambient }} \text { and } C_{p} \mathrm{~A} \text { are constants }
\end{aligned}
$$

$$
\begin{array}{ll}
y(t)=T(t)-T \infty & \text { Temperature difference between stored medium and air temperature } \\
y(0)=T(0)-T \infty=T o-T \infty & \text { Initial temperature difference at } \mathrm{t}=0 \\
\frac{d y}{d t}=\frac{d}{d t}\left(T(t)-T_{\infty}\right)=\frac{d T}{d t}-\frac{d T \infty}{d t}=\frac{d T}{d t}=-k\left(T_{o}-T_{\infty}\right)=-k y(t) \\
\frac{d y}{d t}=-k y(t) \\
\frac{d y(t)}{d t}=-k \\
y(t) \\
\int \frac{d y(t)}{d t} d t=\int-k d t \\
\ln (y(t)=-k t+c=c-k t \\
y(t)=e^{C-k t} \\
y(t)=c e^{-k t} \\
c=\left(T_{o}-T_{\infty}\right) \\
T(t)-T_{\infty}=\left(T_{o}-T_{\infty}\right) e^{-k t}
\end{array}
$$

$$
T(t)=T_{\infty}+\left(T_{o}-T_{\infty}\right) e^{-k t}
$$

Equation 3 - Algorithmic Buffer Equation

From Equation 3 above, an algorithmic model can be used to predict the thermal response of any shape, volume and material while using only air temperature. It should be noted, using the above method in bodies of simple geometry, e.g. cylinders, spheres, the error introduced by the assumption of uniform body temperature will be less than $5 \%$. (Bergman, 2017) This formula was tested by comparing the theoretical data using Equation 3 and physical glycol buffering of the same size. The result was as the model predicted, the error was observed to be $+5 \% /-3 \%$. Demonstrated in an independent study, the accurate derivation of the constant $k$ results in a much more accurate representation of the temperature of the stored contents with an error of .5\%. (Rusnack, 2018) . With the ability to represent the temperature of the stored goods, while providing an equivalency of buffering the air temperature, it is no longer necessary to utilize a physical buffer. The recorded raw air temperature can be acted upon providing data that would be otherwise masked by a buffered temperature. 


\section{Conclusion}

This paper has attempted to quantify an intuitively obvious fact: that thermal buffers of different size and composition will react differently to changes in ambient temperature. The actual consequences of this discrepancy will depend upon the sensitivity of the store goods. With the increasing presence of biological drugs and their synthetic version "biosimilars" this would seem to be an increasingly important issue.

Selection of the thermal buffer that is used in the monitoring of temperature sensitive materials should not be simply left to the provider of the monitor system. It should be accomplished with great care and understanding of the desired outcome. The following should be considered in the selection process:

- What are the physical properties of the materials being stored?

- What is the range of package sizes being stored?

- What is the buffer material selected as the buffer?

Knowing these three factors, one can properly size the buffer that will accurately represent the temperature of the stored goods while providing true and timely notification in the event of a temperature excursion.

In those situations where the stored goods are encased in a variety of enclosures, or when they may vary from time to time, it is obviously impossible to accomplish this completely. The option of "virtual temperature buffering "could be the best solution to these situations.

Conflict of Interest: none

Funding: none

\section{References}

1. Aldous, J. (2017, March 16). How to select a Thermal Buffer from Glycol, Sand, Glass Beads, or Solid Material Blocks. Temperature Probe Buffer Types for Pharmaceutical \& Biotech Temperature Monitoring Applications. Retrieved August 22, 2017, from http://www.vaisala.com/en/lifescience/blog/Lists/P osts/Post.aspx?ID=149

2. A-to-Z Guide to Thermodynamics, Heat \& Mass Transfer, and Fluids Engineering. (2011, Feb 2). doi:10.1615/AtoZ.b.biot_number

3. Bergman, T. L. (2017). Fundamentals of Heat and Mass Transfer. Wiley Global Education. Retrieved from https://books.google.com/books?id=vvyloXEywMoC $\& q=b i o t \# v=$ snippet $\& q=b i o t \& f=f a l s e$
4. Brunning, C. I. (2015, Feb 10). A Summary of Common Vaccine Components. Cambridge, UK. etrieved August 25, 2017, from

http://www.compoundchem.com/2015/02/10/vacci nes/

5. Building Automation Products, Inc. (2014, July 14). Thermobuffer Time Delay. Gays Mills, WI. Retrieved August 23, 2017, from http://www.bapihvac.com/wpcontent/uploads/Thermobuffer_Time_Delay.pdf

6. CDC. (January, 2018). Vaccine Storage adn Handling Toolkit. Retrieved from https://www.cdc.gov/vaccines/hcp/admin/storage/t oolkit/storage-handling-toolkit.pdf

7. Chojnacky, M. J. (2015, September). Optimizing Data Logger Setup and Use for Refrigerated Vaccine Temperature Monitoring. NCSLI Measure J. Meas. Sci., 10(3), 28-37. Retrieved Aug 23, 2017, from http://ws680.nist.gov/publication/get_pdf.cfm?pub _id $=916348$

8. Common solids - like brick, cement, glass and many more - and their specific heats - in Imperial and SI units. (n.d.). Retrieved from Specific Heat of Solids: http://www.engineeringtoolbox.com/specific-heatsolids-d_154.html

9. GDP Question: When to use Mean Kinetic Temperature Calculation (MKT)? (2014, July 5). Retrieved from GMP Compliance.ORG: https://www.gmp-compliance.org/gmp-news/gdpquestion-when-to-use-mean-kinetic-temperaturecalculation-mkt

10. Peeples, L. (2009, August 4). How Many Candies Are in that Jar? Journal of Nature. Retrieved from https://www.scientificamerican.com/article/countin g-candy-jar-packing-density/

11. Resnick, H. a. (2013). Fundamentals of Physics. Wiley.

12. Rusnack, M. R. (2018, February 20). Improving Vaccine Safety by Using an Algorithmic Model as a Replacement for a Physical Thermal Buffer. Innovations in Pharmacy, 8(1). doi:https://doi.org/10.24926/iip.v9i1.962

13. Thompson, S. (2014, March 18). Comparison of Thermal Buffer Effectiveness. Retrieved August 23, 2017, from https://www.dataloggerinc.com/wpcontent/uploads/2017/01/thermal_buffer_temperat ure_monitoring_cas_dataloggers.pdf

14. USFDA. (2014, May 1). Common Ingredients in U.S. Licensed Vaccines. Vaccines, Blood \& Biologics. Silver Springs, MD. Retrieved August 25, 2017, from https://www.fda.gov/BiologicsBloodVaccines/Safety Availability/VaccineSafety/ucm187810.htm 